\title{
Relation of cigarette smoking and mood disorders to cognitive impairment progression
}

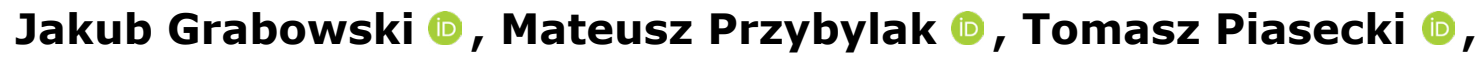 \\ Leszek Bidzan $(1)$
}

Department of Developmental Psychiatry, Psychotic and Geriatric Psychiatry, Faculty of Medicine, Medical University of Gdańsk, Poland

\begin{abstract}
Background: Both depressive disorders and nicotine use are proven and important risk factors of dementia. The purpose of this study was to verify if cigarette smoking and depression symptoms together are disadvantageous for the prognosis in mild cognitive impairment. Material and methods: A total of 43 patients with a diagnosis of mild cognitive impairment were included in the study. ADAS-Cog was performed upon inclusion in the study and again at least 2 years later. Additionally, patients with $\geq 18$ points in MADRS were qualified as depressive. The Fagerström scale for nicotine dependence was administered to smokers. Results: Our study shows a relation between severity of depressive symptoms and further deterioration of cognitive functions according to ADAS-cog scale. Regression analysis revealed that smoking associated with severity of depressive disorders is also correlated with the progression of cognitive impairment. Conclusions: The results of our study are based on a small number of subjects and should be regarded as early findings. Moreover, nicotine dependency should not be regarded as an isolated factor affecting mood disorders and cognitive impairment progression. Further studies on larger groups of patients and using more sensitive methods of cognitive function assessment are needed.
\end{abstract}

Keywords: mild cognitive impairment $\cdot$ nicotine dependency $\cdot$ depression

\section{Citation}

Grabowski J, Przybylak M, Piasecki T, Bidzan L. Relation of cigarette smoking and mood disorders to cognitive impairment progression. Eur J Transl Clin Med. 2020;3(2):29-36.

DOI: $10.31373 /$ ejtcm/127396

Corresponding author:

Jakub Grabowski, Department of Developmental Psychiatry, Psychotic and Geriatric Psychiatry, Faculty of Medicine,

Medical University of Gdańsk, Poland

e-mail: jakub.grabowski@gumed.edu.pl

No external funds.

$\underset{\substack{\text { TRANSPARENT } \\ \text { PROCESS }}}{\substack{\text { OPEN } \\ \text { ACCESS }}}$

Available online: www.ejtcm.gumed.edu.pl

This is Open Access article distributed under the terms of the Creative Commons Attribution-ShareAlike 4.0 International. 


\section{Introduction}

Tobacco smoking is a very common habit and concerns all age groups [1]. Unfortunately, it is also an important health problem among the elderly [2]. Negative health impact of nicotine use, as well as its positive, though transient, effect on concentration after a one-time exposure to nicotine have been known for many years [3]. On the other hand, relatively little has been known on neurobiological effects of chronic smoking, but the number of studies pointing at a negative impact of tobacco use on numerous aspects of cognitive functioning has significantly increased during the last years. This influence has been observed in all ages and seems to apply to information processing speed and memory functioning at the most [4]. The problems mentioned above can be amplified by deficits which appear as early as in the middle age, e.g. those concerning verbal information memorizing, operational memory, executive functions, the speed of cognitive processes, as well as globally worse results in cognition tests [5-8].

Cognitive deterioration related to chronic smoking is based on brain atrophy which advances faster than in non-smokers [9]. Acceleration of degenerative process is visible in brain neuroimaging [10-11]. Taking the above into consideration, smoking can be regarded as an important risk factor of dementia. This suggestion is confirmed mainly by longitudinal studies aiming at identification of dementia risk factors [12].

Smoking has been associated with a number of psychiatric disorders for a long time now [13-14]. The pathogenesis and course of depressive disorders show a certain correlation with tobacco use [15-16]. Relation between smoking and depression is supposed to apply to various aspects of the disease. Although the influence of nicotine dependence on the development of depression is not usually confirmed, the impact of smoking on intensity of symptoms is much underlined [17]. This includes the correlation between severity of depression and the amount of cigarettes smoked [15]. Such studies pay little attention to the assessment of cognitive functions. Some data suggest the association between smoking and depression may be limited to certain symptoms [18].

Mood disorders also tend to have a significant impact on cognition [19]. One may expect, that this influence may increase with coexistent neurobiologic cause, such as cognitive deterioration associated with ageing [20]. Mood disorders, especially depression, are considered a well-known risk factor for dementia mainly, because they precede its appearance relatively often [21]. However, there is also a reverse correlation. Alzheimer or vascular type histochemical alterations of the brain are known to conduce depressive disorders [22].

Mild cognitive impairment $(\mathrm{MCl})$ is another factor which increases the risk of faster neurocognitive deterioration [23-24]. Despite the progress in research on $\mathrm{MCl}$, there is still controversy regarding the diagnosis, its criteria, range and particularly prognosis. Estimation of cognitive deterioration risk factors, as it is based on available data, shows that patients with a diagnosis of $\mathrm{MCl}$ who are smokers and show concurrent depressive symptoms are more susceptible to the development of dementia.

The purpose of this study was to verify the hypothesis stating that cigarette smoking and depression symptoms together are disadvantageous for the prognosis of mild cognitive impairment.

\section{Materials and methods}

We recruited the study cohort from among the patients of a single psychiatric outpatient clinic during six consecutive months.

Inclusion criteria for the study:

- informed consent,

- age above 65 years,

- score of 3 (mild cognitive decline) in Global Deterioration Scale (GDS) [25],

- Mini Mental State Examination (MMSE) score of 24 or more [26].

Exclusion criteria for the study:

- diagnosis of dementia regardless of etiology,

- MMSE score below 24,

- Hachinski Ischaemic Scale score 4 or more [27],

- any of the following diseases present at the time of the study or reported by the patient: bipolar disorder, schizophrenia, alcohol dependency, drug or psychoactive substances dependency, epilepsy, Parkinson's disease, mental retardation, consciousness impairment,

- musculoskeletal, auditory or visual impairment during examination which could influence following the directions and procedures in applied clinical scales,

- other serious somatic diseases, particularly in decompensation.

The Alzheimer's Disease Assessment Scale - cognitive subscale (ADAS-cog) and Montgomery-Asberg Depression Rating Scale (MADRS) were performed at inclusion [28-29]. MADRS score of $\geq 18$ qualified the 
participant to the group of patients with depressive symptoms. The second assessment with ADAS-cog has been repeated after at least two years.

Additionally, to estimate the intensity of tobacco smoking, detailed history was taken from the participant and, if possible, that information was verified by a relative. Specifically, we sought to determine how long the participant has been smoking (in years) and the average amount of cigarettes smoked per day. We qualified the participant as a smoker, if during lifetime he smoked for a period of one year continuously every day, regardless of the number of cigarettes smoked. The participants who were actively smoking also performed the Fagerström Test for Nicotine Dependence [30].

Results were collected on Microsoft Excel 2010 (Microsoft, Redmond, USA). Statistical analysis was performed on Statistica 12.0 (StatSoft Inc./Dell Software, Round Rock, USA). Obtained data was verified statistically by parametric tests (t for two independent means). The predetermined significance level ( $p$ value) was 0,05 for all applied statistical tests. Test results for which significance level was $\leq 0,05$ were deemed as statistically significant. Two-sided confidence interval was adopted. Multivariate multiple regression was used for further analysis of variables.

\section{Results}

Of the initial 1567 patients we screened, 43 were finally included in the study. The ADAS-cog scale was repeated after 24-48 months in 26 participants. The most frequent reason for not administering the scale again was losing contact with participants due to their failure to attend an appointment at the clinic. Sixteen of those participants were qualified as smokers ( 9 of them as past smokers and 7 as active smokers) and 10 as non-smokers.

For the purpose of the study, only data gathered from participants examined with ADAS-cog scale twice was analyzed ( $n=26$ ) (see Graph 1 ). Our results, despite being based on a small number of participants, show a correlation of depressive symptoms (as an overall MADRS score) and further cognitive decline according to ADAS-cog (see Table 1). There is no proven correlation regarding second of the analyzed factors, smoking. Although comparing past or active smokers with participants who have never smoked seems to show a tendency, it is not statistically relevant $(\mathrm{t}=$ -1,42) (see Graph 2). Detailed comparisons with regards to smoking status (past, current and non-smokers) are available in supplementary tables: $\underline{h t t p s: / /}$ ejtcm.gumed.edu.pl/files/61.

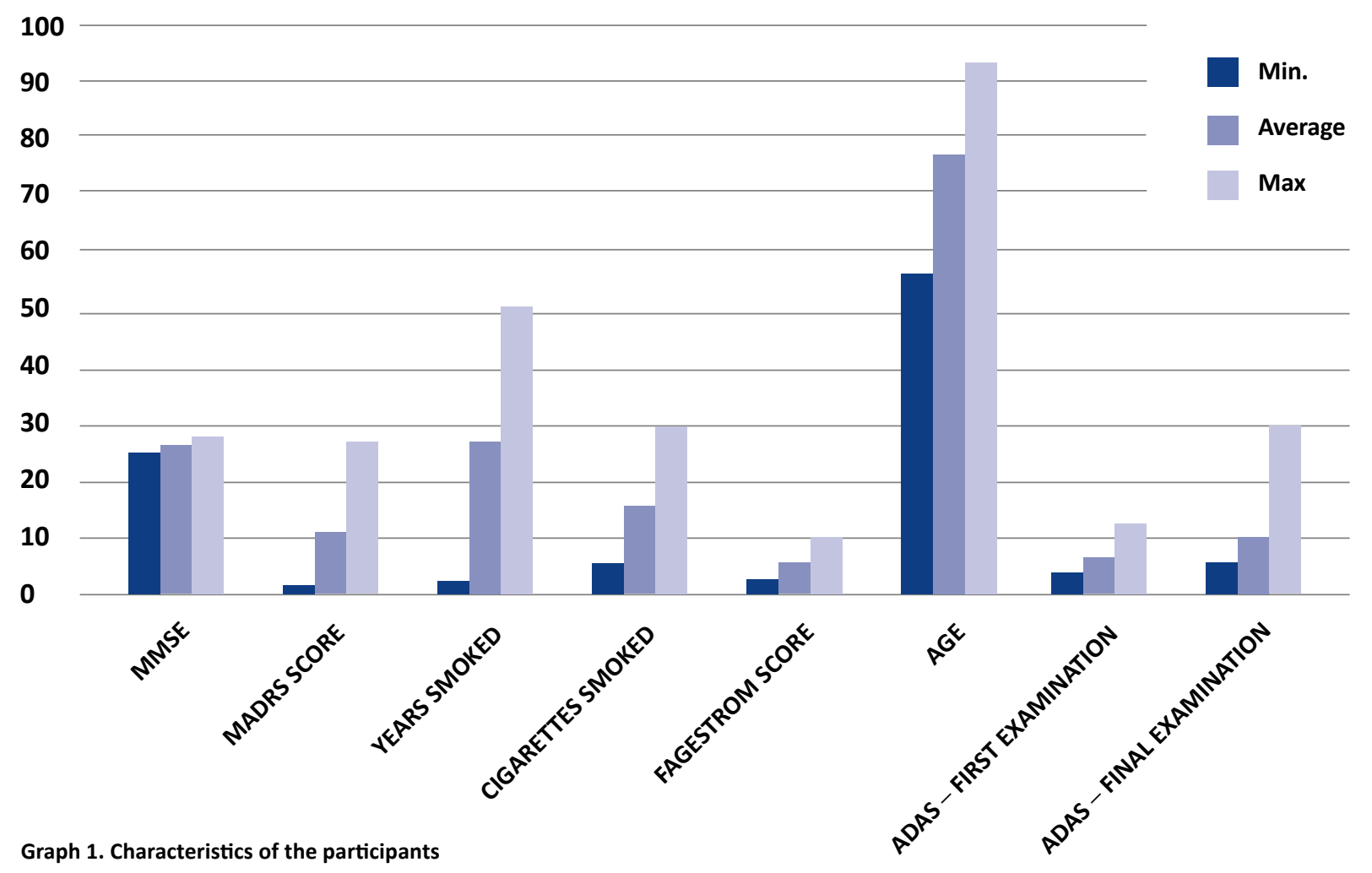

Note: Years smoked, cigarettes smoked and Fagerstrom score apply to smokers only $(\mathbf{N}=16)$

ADAS - Alzheimer's Disease Assessment Scale - cognitive subscale (ADAS-cog);

MMSE - Mini-Mental State Examination; MADRS - Montgomery-Asberg Depression Rating Scale 
Table 1. Comparison of subjects with the Montgomery-Asberg Depression Rating Scale (MADRS) scores of $<18$ and $\geq 18$ points

\begin{tabular}{|c|c|c|c|c|}
\hline $\begin{array}{c}\text { Mean } \\
\text { MADRS } \\
\mathbf{1} \text { 18pts }\end{array}$ & $\begin{array}{c}\text { Mean } \\
\text { MADRS } \\
\mathbf{N}=18 \text { pts } \\
(\mathbf{N}=\mathbf{9})\end{array}$ & $\mathbf{T}$ & $\mathbf{d f}$ & $\mathbf{P}$ \\
\hline 75,35 & 79,55 & $-0,94$ & 24 & 0,37 \\
\hline 25,82 & 24,33 & 3,91 & 24 & 0,00 \\
\hline 6,59 & 8,89 & $-2,93$ & 24 & 0,00 \\
\hline 7,65 & 13,33 & $-4,21$ & 24 & 0,00 \\
\hline 1,12 & 4,55 & $-2,98$ & 24 & 0,01 \\
\hline 6,12 & 21,55 & $-9,78$ & 24 & 0,00 \\
\hline
\end{tabular}

Difference in ADAS scores between first and final examination calculated in points. ADAS - Alzheimer's Disease Assessment Scale cognitive subscale (ADAS-cog); df - degrees of freedom; MARDS -Montgomery-Asberg Depression Rating Scale; MMSE - Mini-Mental State Examination; $\mathbf{N}$ - number of subjects; $\mathbf{P}$ - statistical significance; $\mathrm{T}$ - random variable

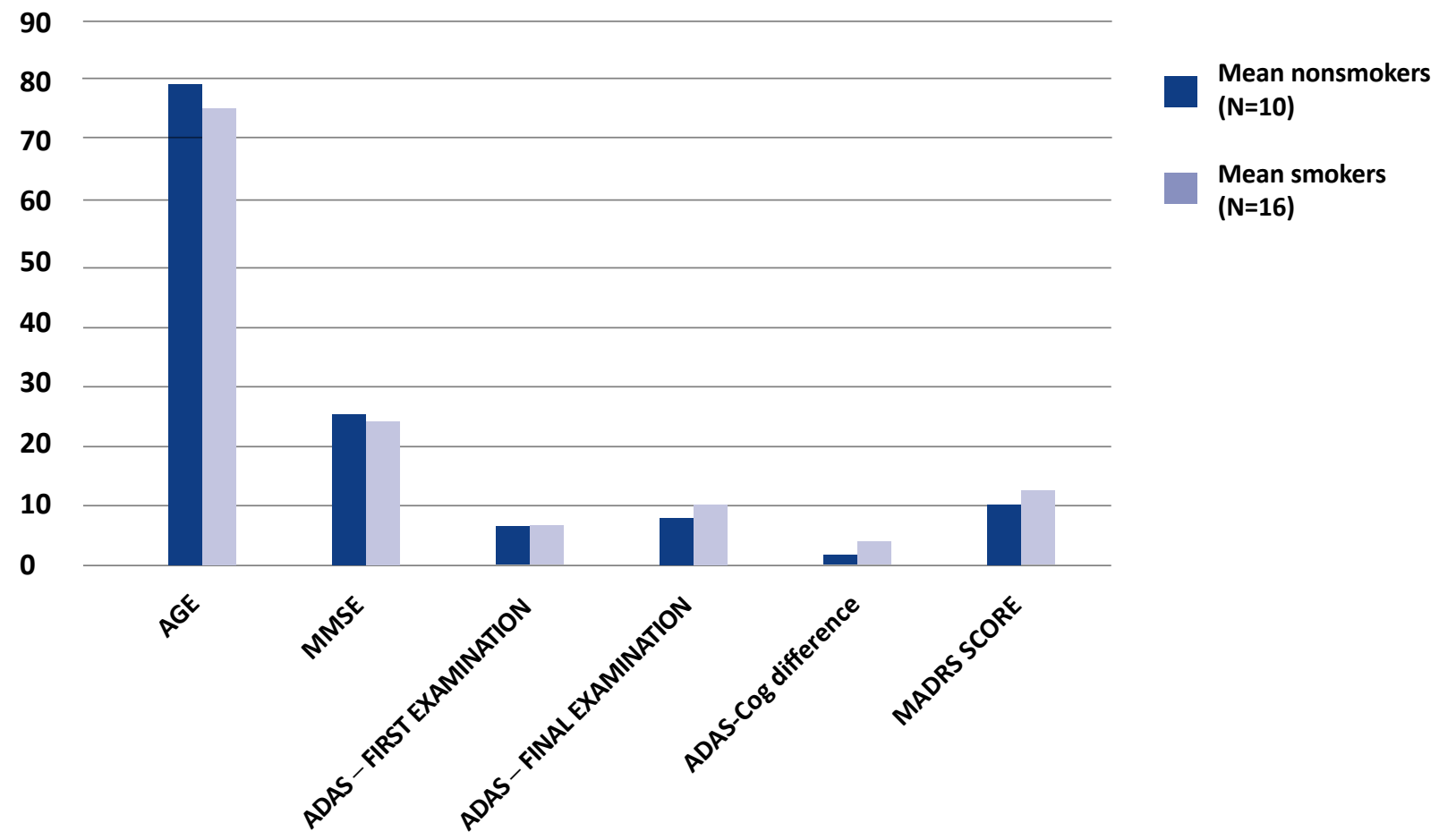

Graph 2. Comparison of non-smokers with smokers (present and past)

Difference in ADAS scale scores between first and final examination calculated in points. P > 0,05 for all results. ADAS - Alzheimer's Disease Assessment Scale - cognitive subscale (ADAS-cog); MADRS - Montgomery-Asberg Depression Rating Scale; MMSE - Mini-Mental State Examination; $\mathbf{N}-$ number of subjects 
Regression analysis shows a relation between smoking in combination with the severity of depressive disorders and cognitive impairment progression (see Table 2).

Table 2. Multiple regression analysis (dependent variable of ADAS-cog scale difference in points between baseline score and upon follow-up 2 years later)

\begin{tabular}{|c|c|}
\hline $\begin{array}{c}\text { Independent } \\
\text { variables }\end{array}$ & $\begin{array}{c}\text { Beta } \\
\text { coefficient }\end{array}$ \\
\hline YEARS SMOKED & 0,777 \\
\hline CIGARETTES SMOKED & $-0,09$ \\
\hline \multicolumn{2}{|c|}{0,49} \\
\hline Multiple R $=\mathbf{0 , 8 1 9 9 1 8 0 9}$ \\
\hline F $=\mathbf{8 , 2 0 5 0 0 8}$ \\
\hline SD: $\mathbf{2 , 2 4 8 6 5 4}$ \\
\hline T(12) $=\mathbf{1 , 3 0 6 5}$ \\
\hline P $=\mathbf{0 , 2 1 5 9}$ \\
\hline
\end{tabular}

MADRS - Montgomery-Asberg Depression Rating Scale; N - number of subjects; P - statistical significance; SD - standard deviation; $\mathrm{T}$ - random variable

\section{Discussion}

A variety of data implies that both smoking and depressive disorders show a certain correlation with the rate of cognitive decline [31-32] . It is still a matter of discussion whether these can be viewed as separate factors or if their mutual influences modulate the intensity of impact. Some observations on codependence of cigarette smoking and mood disorders seem to suggest the latter $[15,17]$. On the other hand, there are multiple factors behind nicotine dependence or depression, such as some personality predispositions, which in turn can be an outcome of mechanisms associated with neurobiological conditioning of cognitive disorders progress.
It is a fact that both mood disorders and smoking do not always show a correlation with cognitive decline. A symptomatic example is proven lack of influence of smoking in patients with ApoE 4 [33-34]. Although one may expect that an accumulation of a so-called strong risk factor (e.g. ApoE 4) with a potential risk factor (e.g. cigarette smoking) may increase the effect of the latter, this is not the case.

The relation of depression and cognitive functions deterioration has caught a lot of attention, but the mechanism is still not known. One of the hypotheses assumes that depression induces chronic stress dysregulation, which may lead to hippocampal structures damage [35-36]. A major problem in evaluating this occurrence is a great difficulty in differentiating early stages of dementia, which often manifest themselves as mood worsening and other depressive symptoms [37]. This does not diminish the meaning of depression as a risk factor, it may however draw doubt when attempting to establish its role in the pathogenesis of the process. It seems that both disorders (depression and dementia) are a result of the same neurobiological process.

A basis for assessing mood disorders in the examined group was MADRS, which is probably the most commonly used depression scale, instead of the diagnosis of depression according to the classification criteria. This decision was made taking into consideration fact, that depression in elderly patients, especially when coexistent with cognitive disorders, tend to have atypical clinical picture, not compliant with diagnostic criteria. Consequently, ascertaining depressive symptoms is far more often than asserting depressive episode [38].

The concept of 'cigarette smoking' is somewhat imprecise. One needs to realize that cigarette smoke contains around 4000 components, each of them being possibly directly or indirectly harmful to brain functions [39]. Their meaning can differ greatly with regard to many factors including way of smoking, its intensity, period of smoking, age of smoker. Furthermore, particular products from different manufacturers cannot always be compared. Despite the fact that contemporary studies point to an indisputable toxicity of smoking to neurobiological functions and, as a result, to cognition, its mechanism remains in the area of imprecise hypotheses.

Possible mechanisms include direct cytotoxic influence of substances emitted during the process of smoking [40] or possible impact on cognition by generating vascular processes [41] which play a significant role in pathogenesis of dementia - Alzheimer's type or other [42-43]. Moreover people who are not nicoti- 
ne dependent develop a short effect of increasing the number of nicotine receptors and transient improvement in certain aspects of attention. At the same time smoking greatly increases oxidative stress which is another important pathogenesis factor, especially in Alzheimer's disease [44-45]. There are various more potential mechanisms of action of substances emitted during smoking. Those that may be worth mentioning are indirect mechanisms such as a variety of adverse metabolic effects which have a doubtless influence on cerebral processes [46-47]. Some data show that cessation of smoking at a certain point during lifetime does not unfortunately neutralize the potentially harmful impact on cognition in old age [48-49].

Results of our study point to this at some extent. Although the very fact of smoking has not been confirmed as a statistically relevant factor of cognitive impairment progression, the application of regression analysis shows that such a relation exists in combination with the severity of depressive disorders (MADRS).

Taking into account the number of participants, our results should be regarded as early findings, which requires confirmation in the future. The validity of results is also limited by the sensitivity of scale used to assess cognitive functions - ADAS-cog. One may have doubts whether it is a precise enough tool in $\mathrm{MCl}$, where the impairment is, by definition, insignificant. Further studies should be based on more sensitive methods of cognitive functions examination. Eventually, the estimation of smoking habits was in a large part imprecise, which must have had an impact on our results. Moreover it should be considered, that obtained results could be influenced by recall bias related to imprecise collection of this data after so many years and not always from the patient himself.

\section{Conclusions}

Results, despite being based on a small number of participants, show a relation of depressive symptoms (as an overall MADRS score) to further cognitive decline according to ADAS-cog. With regard to the number of participants, a detailed analysis of particular MADRS items has been abandoned, yet earlier studies imply that a relation here may also exist [38].

There is no proven relation regarding second of the analyzed factors, smoking. Although comparing participants who have never smoked with past or current smokers seems to show a tendency to be statistically relevant $(t=-1,42)$. Taking into consideration the postulated complexity of the impact smoking has on cognitive functions, it comes to no surprise that any possible relation would be relatively vague. Regression analysis shows a correlation between smoking in combination with the severity of depressive disorders and cognitive impairment progression.

Acknowledgements: None.

Conflict of interest: None to declare.

\section{References}

1. Jassem J, Przewoźniak K, Zatoński W. Tobacco control in Poland-Successes and challenges [Internet]. Vol. 3, Translational Lung Cancer Research. AME Publishing Company; 2014. p. 280-5. Available from: http://tlcr.amegroups.com/article/ view/3148/3751

2. Suwała M, Gerstenkorn A. Palenie tytoniu i picie alkoholu w wielkomiejskiej populacji osob w starszym wieku. Psychogeriatria Pol [Internet]. 2006;3(4):191-200. Available from: https://fbc.pionier.net.pl/details/nnz2ISz

3. Rezvani AH, Levin ED. Cognitive effects of nicotine. Biol Psychiatry [Internet]. 2001 Feb;49(3):258-67. Available from: https://linkinghub.elsevier.com/retrieve/pii/S0006322300010945

4. Starr JM, Deary IJ, Fox HC, Whalley LJ. Smoking and cognitive change from age 11 to 66years: A confirmatory investigation. Addict Behav [Internet]. 2007 Jan;32(1):63-8. Available from: https://linkinghub.elsevier.com/retrieve/pii/ $\underline{\text { S0306460306000906 }}$

5. Kalmijn S. Cigarette Smoking and Alcohol Consumption in Relation to Cognitive Performance in Middle Age. Am J Epidemiol [Internet]. 2002 Nov 15;156(10):936-44. Available from: https://doi.org/10.1093/aje/kwf135

6. Paul RH, Brickman AM, Cohen RA, Williams LM, Niaura R, Pogun S, et al. Cognitive status of young and older cigarette smokers: Data from the international brain database. J Clin Neurosci [Internet]. 2006 May;13(4):457-65. Available from: https://linkinghub.elsevier.com/retrieve/pii/S0967586806000154

7. Caspers K, Arndt S, Yucuis R, McKirgan L, Spinks R. Effects of Alcohol- and Cigarette-Use Disorders on Global and Specific Measures of Cognition in Middle-Age Adults*. J Stud Alcohol Drugs [Internet]. 2010 Mar;71(2):192-200. Available from: http://www.jsad.com/doi/10.15288/isad.2010.71.192 
8. Whalley LJ, Fox HC, Deary IJ, Starr JM. Childhood IQ, smoking, and cognitive change from age 11 to 64 years. Addict Behav [Internet]. 2005 Jan;30(1):77-88. Available from: https://linkinghub.elsevier.com/retrieve/pii/S0306460304001601

9. Meyer JS, Rauch GM, Crawford K, Rauch RA, Konno S, Akiyama H, et al. Risk factors accelerating cerebral degenerative changes, cognitive decline and dementia. Int J Geriatr Psychiatry [Internet]. 1999 Dec;14(12):1050-61. Available from: https://onlinelibrary.wiley.com/doi/10.1002/(SICI)1099-1166(199912)14:12\%3C1050::AID-GPS56\%3E3.0.CO;2-Z

10. Kubota K, Matsuzawa T, Fujiwara T, Yamaguchi T, Ito K, Watanabe H, et al. Age-related brain atrophy enhanced by smoking: A quantitative study with computed tomography. Tohoku J Exp Med [Internet]. 1987;153(4):303-11. Available from: http://joi.jlc.jst.go.jp/JST.Journalarchive/tjem1920/153.303?from=CrossRef

11. Brody AL, Mandelkern MA, Jarvik ME, Lee GS, Smith EC, Huang JC, et al. Differences between smokers and nonsmokers in regional gray matter volumes and densities. Biol Psychiatry [Internet]. 2004 Jan;55(1):77-84. Available from: https:// linkinghub.elsevier.com/retrieve/pii/S0006322303006103

12. Peters R, Poulter R, Warner J, Beckett N, Burch L, Bulpitt C. Smoking, dementia and cognitive decline in the elderly, a systematic review. BMC Geriatr [Internet]. 2008 Dec 23;8(1):36. Available from: http://www.ncbi.nlm.nih.gov/pubmed/19105840

13. de Leon J, Becona E, Gurpegui M, Gonzalez-Pinto A, Diaz FJ. The Association Between High Nicotine Dependence and Severe Mental IIIness May Be Consistent Across Countries. J Clin Psychiatry [Internet]. 2002 Sep 15;63(9):812-6. Available from: http://article.psychiatrist.com/?ContentType=START\&ID=10001564

14. John U, Meyer C, Rumpf H-J, Hapke U. Smoking, nicotine dependence and psychiatric comorbidity-a population-based study including smoking cessation after three years. Drug Alcohol Depend [Internet]. 2004 Dec 7;76(3):287-95. Available from: https://linkinghub.elsevier.com/retrieve/pii/S0376871604001619

15. Covey LS, Tam D. Depressive mood, the single-parent home, and adolescent cigarette smoking. Am J Public Health [Internet]. 1990 Nov;80(11):1330-3. Available from: http://ajph.aphapublications.org/doi/10.2105/AJPH.80.11.1330

16. Martini S, Wagner FA, Anthony JC. The association of tobaco smoking and depression in adolescence: evidence from the United States. Subst Use Misuse [Internet]. 2002 Jan 1;37(14):1853-67. Available from: https://www.tandfonline.com/ doi/full/10.1081/JA-120014087

17. Goodman E, Capitman J. Depressive symptoms and cigarette smoking among teens. Pediatrics [Internet]. 2000;106(4):74855. Available from: https://pediatrics.aappublications.org/content/106/4/748.short

18. Patten CA, Gillin JC, Golshan S, Wolter TD, Rapaport M, Kelsoe J. Relationship of mood disturbance to cigarette smoking status among 252 patients with a current mood disorder. J Clin Psychiatry [Internet]. 2001 May 15;62(5):319-24. Available from: http://article.psychiatrist.com/?ContentType=START\&ID $=10001640$

19. Miller WR. Psychological deficit in depression. Psychol Bull [Internet]. 1975 Mar;82(2):238-60. Available from: http://doi. apa.org/getdoi.cfm?doi=10.1037/h0076367

20. Reifler B V., Larson E, Hanley R. Coexistence of cognitive impairment and depression in geriatric outpatients. Am J Psychiatry [Internet]. 1982 May;139(5):623-6. Available from: http://psychiatryonline.org/doi/abs/10.1176/ajp.139.5.623

21. Paterniti S, Verdier-Taillefer M-H, Dufouil C, Alpérovitch A. Depressive symptoms and cognitive decline in elderly people. Br J Psychiatry [Internet]. 2002 Nov 2;181(5):406-10. Available from: http://www.ncbi.nlm.nih.gov/pubmed/12411266

22. Cummings JL, Miller B, Hill MA, Neshkes R. Neuropsychiatric Aspects of Multi-infarct Dementia and Dementia of the Alzheimer Type. Arch Neurol [Internet]. 1987 Apr 1;44(4):389-93. Available from: http://archneur.jamanetwork.com/ article. aspx?articleid $=586308$

23. Hänninen T, Hallikainen M, Tuomainen S, Vanhanen M, Soininen H. Prevalence of mild cognitive impairment: a population-based study in elderly subjects. Acta Neurol Scand [Internet]. 2002 Sep;106(3):148-54. Available from: http://www. ncbi.nlm.nih.gov/pubmed/12174174

24. Flicker C, Ferris SH, Reisberg B. Mild cognitive impairment in the elderly: Predictors of dementia. Neurology [Internet]. $1991 \mathrm{Jul}$ 1;41(7):1006-1006. Available from: http://www.neurology.org/cgi/doi/10.1212/WNL.41.7.1006

25. Reisberg B, Ferris SH, De Leon MJ, Crook T. The Global Deterioration Scale for assessment of primary degenerative dementia. Am J Psychiatry [Internet]. 1982 Sep;139(9):1136-9. Available from: http://psychiatryonline.org/doi/abs/10.1176/ajp.139.9.1136

26. Folstein MF, Folstein SE, McHugh PR. “Mini-mental state". J Psychiatr Res [Internet]. 1975 Nov;12(3):189-98. Available from: https://linkinghub.elsevier.com/retrieve/pii/0022395675900266

27. Hachinski VC, Iliff LD, Zilhka E, Du Boulay GH, McAllister VL, Marshall J, et al. Cerebral Blood Flow in Dementia. Arch Neurol [Internet]. 1975 Sep 1;32(9):632-7. Available from: http://archneur.jamanetwork.com/article.aspx?articleid=573931

28. Rosen WG, Mohs RC, Davis KL. A new rating scale for Alzheimer's disease. Am J Psychiatry [Internet]. 1984 Nov;141(11):1356-64. Available from: http://psychiatryonline.org/doi/abs/10.1176/ajp.141.11.1356

29. Montgomery SA, Åsberg M. A New Depression Scale Designed to be Sensitive to Change. Br J Psychiatry [Internet]. 1979 Apr 29;134(4):382-9. Available from: https://www.cambridge.org/core/product/identifier/S0007125000058487/type/ journal article 
30. Fagerström K-O. Measuring degree of physical dependence to tobacco smoking with reference to individualization of treatment. Addict Behav [Internet]. 1978 Jan;3(3-4):235-41. Available from: https://linkinghub.elsevier.com/retrieve/ pii/0306460378900242

31. Silverstein NM, Flaherty G, Tobin TS. Dementia and Wandering Behavior: Concern for the Lost Elder [Internet]. Springer Publishing Company; 2006. Available from: https://books.google.pl/books/about/Dementia and Wandering Behavior. html?id=vPK6lijpje8C\&redir esc=y

32. Reding M. Depression in Patients Referred to a Dementia Clinic. Arch Neurol [Internet]. 1985 Sep 1;42(9):894. Available from: http://archneur.jamanetwork.com/article.aspx?doi=10.1001/archneur.1985.04060080080019

33. Reitz C, Luchsinger J, Tang M-X, Mayeux R. Effect of smoking and time on cognitive function in the elderly without dementia. Neurology [Internet]. 2005 Sep 27;65(6):870-5. Available from: http://www.neurology.org/cgi/doi/10.1212/01. wnl.0000176057.22827.b7

34. Negash S, Greenwood PM, Sunderland T, Parasuraman R, Geda YE, Knopman DS, et al. The influence of apolipoprotein E genotype on visuospatial attention dissipates after age 80. Neuropsychology [Internet]. 2009;23(1):81-9. Available from: http://doi.apa.org/getdoi.cfm?doi=10.1037/a0014014

35. Rubinow DR. Cortisol Hypersecretion and Cognitive Impairment in Depression. Arch Gen Psychiatry [Internet]. 1984 Mar 1;41(3):279.Availablefrom: http://archpsyc.jamanetwork.com/article.aspx?doi=10.1001/archpsyc.1984.01790140069008

36. Laakso MP, Soininen H, Partanen K, Helkala EL, Hartikainen P, Vainio P, et al. Volumes of hippocampus, amygdala and frontal lobes in the MRI-based diagnosis of early Alzheimer's disease: Correlation with memory functions. J Neural Transm - Park Dis Dement Sect [Internet]. 1995 Feb;9(1):73-86. Available from: http://link.springer.com/10.1007/BF02252964

37. Geerlings MI, Bouter LM, Schoevers RA, Beekman ATF, Jonker C, Deeg DJH, et al. Depression and risk of cognitive decline and Alzheimer's disease. Br J Psychiatry [Internet]. 2000 Jun 2;176(6):568-75. Available from: https://www.cambridge. org/core/product/identifier/S0007125000154662/type/journal article

38. Bidzan L, Bidzan M. Depressive symptoms and preclinical Alzheimer's disease. Arch Psychiatry Psychoter [Internet]. 2005;7(3):13-7. Available from: http://www.archivespp.pl/uploads/APPv7n3p13Bidzan.pdf

39. Bates C, Connoly G, Jarvis M, Fund I. Tobacco additives: Cigarette engineering and nicotine addiction: A survey of the additive technology used by cigarette manufacturers to enhance the [Internet]. 1999 [cited 2020 Oct 13]. Available from: https:// www.researchgate.net/publication/242598454 Tobacco Additives Cigarette Engineering and Nicotine Addiction

40. Fowles J, Bates M. The Chemical Constituents in Cigarettes and Cigarette Smoke: Priorities for Harm Reduction Investigation of Ocular, Heart and Lung Diseases and Household Fuel Use in Kaski District, Nepal View project Nepal TB Study View project [Internet]. A Report to the New Zealand Ministry of Health. 2000. Available from: https://www.researchgate.net/ profile/Michael Bates3/publication/265540805 The Chemical Constituents in Cigarettes and Cigarette Smoke Priorities for Harm Reduction/links/56feb91708ae650a64f72556/The-Chemical-Constituents-in-Cigarettes-and-Cigarette-Smoke-Priorities-for-Harm-Reduction.pdf

41. Jee SH, Suh I, Kim IS, Appel LJ. Smoking and Atherosclerotic Cardiovascular Disease in Men With Low Levels of Serum Cholesterol. JAMA [Internet]. 1999 Dec 8;282(22):2149. Available from: http://jama.jamanetwork.com/article.aspx?doi=10.1001/jama.282.22.2149

42. Rockwood K, Ebly E, Hachinski V, Hogan D. Presence and Treatment of Vascular Risk Factors in Patients With Vascular Cognitive Impairment. Arch Neurol [Internet]. 1997 Jan 1;54(1):33-9. Available from: http://archneur.jamanetwork. com/article.aspx?articleid $=594392$

43. Kalaria RN. Cerebral vessels in ageing and Alzheimer's disease. Pharmacol Ther [Internet]. 1996 Jan;72(3):193-214. Available from: https://linkinghub.elsevier.com/retrieve/pii/S0163725896001167

44. Perry G, Cash AD, Smith MA. Alzheimer Disease and Oxidative Stress. J Biomed Biotechnol [Internet]. 2002;2(3):120-3. Available from: $\underline{\text { http://www.hindawi.com/journals/bmri/2002/542340/abs/ }}$

45. Moriarty S. Oxidation of glutathione and cysteine in human plasma associated with smoking. Free Radic Biol Med [Internet]. 2003 Dec 15;35(12):1582-8. Available from: https://linkinghub.elsevier.com/retrieve/pii/S0891584903005987

46. Chiolero A, Faeh D, Paccaud F, Cornuz J. Consequences of smoking for body weight, body fat distribution, and insulin resistance. Am J Clin Nutr [Internet]. 2008 Apr 1;87(4):801-9. Available from: https://academic.oup.com/ajcn/article/87/4/801/4633357

47. Convit A. Links between cognitive impairment in insulin resistance: An explanatory model. Neurobiol Aging [Internet]. 2005 Dec;26(1):31-5. Available from: https://linkinghub.elsevier.com/retrieve/pii/S0197458005002691

48. Stewart MCW, Deary IJ, Fowkes FGR, Price JF. Relationship between Lifetime Smoking, Smoking Status at Older Age and Human Cognitive Function. Neuroepidemiology [Internet]. 2006 Feb;26(2):83-92. Available from: https://www.karger. com/Article/FullText/90253

49. Fischer P, Zehetmayer S, Bauer K, Huber K, Jungwirth S, Tragl K-H. Relation between vascular risk factors and cognition at age 75. Acta Neurol Scand [Internet]. 2006 Aug;114(2):84-90. Available from: http://doi.wiley.com/10.1111/i.1600-0404.2006.00597.x 